\title{
Possibilities of digital platforms in solving various educational problems in the digital space
}

\author{
N.N. Lukasheva ${ }^{1 *}$, E.K. Ametova ${ }^{2}$, and N.S. Matyukhina ${ }^{3}$ \\ ${ }^{1}$ V.I. Vernadsky Crimean Federal University, Simferopol, Russia \\ ${ }^{2}$ V.I. Vernadsky Crimean Federal University, Simferopol, Russia \\ ${ }^{3}$ V.I. Vernadsky Crimean Federal University, Simferopol, Russia
}

\begin{abstract}
This article examines the current problems of digitalization of education. The author analyzes the essence of digitalization and the emergence of new digital technologies that represent great pedagogical potential. The possibility of using digital technologies in the process of passing compulsory practice by students is also considered. This article describes the digital education environment. The conceptual framework has been clarified: "digital literacy", "digital educational environment". The digital education strategy provides for promising innovative technologies. The author comes to the conclusion that the digitization of education has changed the content of the courses given by teachers, as well as the presentation of information - this is not only a presentation or a video, it is already directly connected databases and forums to the Information Network. The concepts of digital platforms are systematized, the methods and basic principles of using the functions of digital platforms are grounded, variants for the effective implementation of new educational technologies for online education are proposed.
\end{abstract}

\section{A problem statement}

The urgency of this study is due to the growing prevalence of e-learning in educational institutions. This improves the quality of general education (for example, in small distance schools), ensures the availability of general education (mainly for students with disabilities) and provides opportunities for qualitative general education and additional education at the specialized level. The legal basis for the systematic implementation of distance education is the Federal Law dated on September 29, 2012 No. 273-FL "On education in the Russian Federation" and the Order of the Ministry of Education and Science of the Russian Federation dated on August 23, 2017 No. 816 "On approval of the procedure for the use of e-learning and distance learning methods by organizations carrying out educational activities in the implementation of educational programs".

The worldwide experience shows that, despite the growing popularity, the use of only distance technologies is not always effective enough even among the adult audience:

* Corresponding author: prof-ped.gpa@mail.ru 
students may not have enough motivation and self-organization skills to master and complete the course of study. Therefore, the most promising model today is a hybrid learning model, which implies the integration of e-learning into traditional classroom systems. Today in Russia and other countries there is a rapid transition from educational institutions to distance learning. Each educational organization and each teacher are faced with the acute task of mastering the distance learning format.

The aim of the study is to create and approbate the use of digital educational resources developed on the basis of a modular competence-based approach to distance learning.

The object of the research: the educational process in distance learning.

The subject of the research is the formation and use of digital educational resources developed on the basis of a modular competence-based approach to distance learning.

The study suggests that the effectiveness of distance learning in institutions of secondary vocational education and the level of professional skills will be high.

Digital technologies, social networks and instant messengers have changed social values, which led to the identification of a person on the network. The beginning of a new type of student was laid, who determines his educational trajectory independently. Their motivation is personal development and self-determination combined with work and study.

The education system must ensure a confident transition to a digital age characterized by economic growth and new labor relations. Artificial intelligence should appear on the labor market, performing regular processes [1].

Distance learning (DPO) in institutions of secondary vocational education is called upon solving the priority tasks in the field of education, namely, the introduction of modern educational technologies in the educational process and the training of qualified personnel based on the use of digital educational resources (DPS) of the Internet, which, in turn, forms the ability to search and find the necessary information, to analyze the data obtained, to systematize the results obtained, to prepare and present relevant information competently and effectively.

Expectations from the informatization of education largely depend on the principles of development and quality. Therefore, one of the main tasks of the creators of electronic resources for vocational education is to maximize the effectiveness of new products.

As we all know, computers offer you five new learning tools: interactive, multimedia, modeling, communicative, productive. Its use affects directly the efficiency and quality of digital educational resources. For the time being the first three tools are used mainly for electronic publications in local media, and the last two are for Internet resources. Using all of these learning tools simultaneously, the new generation of digital learning centers is a highly interactive, multimedia focused electronic educational product that is distributed on the global computer network. Solving the problem of creating a network multimedia center requires the development of a unified structure of content components of electronic educational products, as well as the development of a unified software environment in terms of functionality.

To cope with the challenges of digitalization our education must undergo a digital transformation. According to scientists, the digital transformation of education is a response to a global information challenge.

In the works of Storozhilova D.N. it is noted that "focusing on the transition to an interactive type of interaction, students should be able to acquire knowledge independently and produce their own innovative knowledge, thereby forming new abilities in the XXI century, which are called the four "Cs": creativity, critical thinking, communication, cooperation" [2].

In his research Aleksankov A.M. notes that the digital transformation of education should be accompanied by "joint" content updating, which will lead to a fundamental improvement in the quality of education [3]. 
We agree with Aleksankov A.M., who believes that if the education system meets the requirements and capabilities of digital society, then the digital transformation of education will lead society to digital economy.

The modern stage of digitalization of education is that all disciplines are immersed in digital learning environment.

Currently the question of the structure of the components of digital learning environment is controversial. Many scientists are studying the problem of forming digital learning environment.

According to Ignatov N.Yu., digital learning environment should include a semantic value component (goals and objectives of organizing the project process in digital learning environment), procedural methods (normative support for the functioning of the education system), information knowledge (a set of students' competencies), communication (interaction of subjects of the educational process in the DSP) and technology (modern teaching aids in the DSP) [4].

Agibova I.M. believes that the digital learning environment should include such a block as a block for the correction of academic progress, which performs the function of assessing the diagnosis and correction of the trajectory of students' learning [5].

We agree with the point of view of Andreev A.A., who believes that the structure of a DLE should include a block of information, which consists of information systems, services and tools for solving certain problems. Services such as MOODLE have long been used in universities and allow you keep track of changes in the ranks of students and teachers and determine their ratings. Accommodation and information exchange services provided in the personal accounts of students and teachers help to organize joint work of participants in the educational process.

There are quite a lot of services and tools for creating a DTS, and their saturation in a DTS depends on the technical and financial capabilities of the organization [6].

Having analyzed the digitalization of education, we state the emergence of new digital technologies with great pedagogical potential. Among them, the most common is cloud technology. This is a completely new service that allows you to store large amounts of information and has convenient network access to information resources that can be used with minimal administrative effort and interaction with suppliers.

Online education is developing rapidly and today it is already an integral part of nonformal and continuing education. Every new technology in the economic and social fields requires preparation. New and rapidly growing markets are creating the demand for knowledge that did not exist before: virtual reality, electronic printing, electronic design and many other new areas of knowledge. Traditional educational institutions are trying to introduce new educational programs for 2-4 years. But it is too long for the rate of development of all spheres of life today. That is why there is an urgent need for "fast" education, flexible and multilevel. These are the features of online education on digital learning platforms.

Secondary education in Russia in the context of many changes has come close to understanding the need for large-scale implementation of digital learning platforms. Among Russian projects, the following online platforms can be distinguished:

1. Yaklass - one of the best school projects in Scolkovo which helps students to organize work on the topic independently, to get ready for tests or exams;

2. Foxford - allows students from all regions of Russia to study school subjects in an interactive manner;

3. "The Internet. Profile" - with its help you can pass a vocational guidance test, choose a part of additional education and get information about which professions are the most demanded and highly paid at the moment. 
However almost all existing Russian online platforms are focused on providing educational services on a paid basis and, therefore, do not claim to engage a large audience.

The question of the formation of digital platforms for learning has been raised in a number of scientific studies. In the article by N.Ya. Ignatova the needs of the younger generation in digital learning are described [4]. S.D. Karakozov, A.Yu. Uvarov grounded the conditions for the successful informatization of the educational process [7]. In his article A.B. Galanov proposed a methodology for educational activities in the school of telecommunications [8].

However, as a rule, authors study the technical engineering of platforms that do not contemplate feedback from consumers of educational content and do not provide for the organized use of these platforms in the school environment. At the same time publications of recent years unanimously recognize the solution to the problem of introducing new technologies into the economy: "... There is no doubt that the restructuring of the educational process should begin" [8].

As a result, almost all researchers admit that future trends in education are strongly associated with digitalization, which will change the labor market and create conditions for the formation of new competencies, the foundation of which should be laid in schools. The study of the practical activities of modern Russian schools confirms that digital platforms are currently being actively introduced into the practice of developing secondary education and are the subject of comprehensive scientific researches. At the same time we consider it necessary to distinguish some of the problems accompanying the formation of digital learning in Russian schools:

1. Schools do not fully understand the potential of digital platforms in the educational process, do not have a sufficient level of training (regulatory, technical, organizational) to use this potential effectively.

2. It is necessary to clarify the ideology and purpose of using various digital platforms in the general context of the educational process in each school.

3. The lack of criteria for the effectiveness of the usage of digital learning platforms in the school educational process does not allow considering the platform as an integrated part of the educational process.

4. Various platforms, the content of which does not have common ideology and purpose, reduce the adequacy of their options for organized usage in the learning process.

A new model of education has taken form: teaching students to acquire knowledge independently by means of using Internet technologies. Further let's turn our attention to digital learning platforms that contribute learning in a new way, very effectively, creatively and, which is most important, accessibly and understandably to students undergoing practical training.

\subsection{The objective of the work}

During the teaching practice students of the Federal State Autonomous Educational Institution of Higher Education "V.I. Vernadsky Crimean Federal University" in the 20192020 academic year, when working with students of 4th form, began to use two platforms in educational activities: MEL and Yandex-Textbook. They fully correspond to federal state educational standards and contribute to solving the tasks of the Federal Target Program for the Development of Education to improve the efficiency of education and digital literacy of students and teachers. The portal contains a large number of interactive tasks. The platform is very easy to use. After registration, teachers get access to all materials and functions of the site. Username and password are automatically generated for each student. Pupils get to the information platform and the work begins. By the way, this is where one of the digital abilities of elementary school students begins - the ability to access 
the site using a login and password. In the course of work, you can organize courses in various forms: groups, questions, searches, research, etc. With the successful implementation of group activities in MEE, it is worth paying attention to the personalization of the mobile electronic educational content of the educational space, which is based on the acceptance of the uniqueness of the personality of each child, support of his individual needs and interests. Pupils complete assignments at home at a convenient time for them. Interactive, vivid and fun activities are designed to reinforce the skills acquired during the course. By starting the first assignment, learners can gradually gain access to subsequent assignments. These platforms contribute the formation and development of digital skills among students undergoing practice. Doing interesting interactive activities at home and in class certainly increases motivation to learn basic subjects, thereby improving learning results.

\section{Results of the research}

At the end of the two quarters of the 2019-2020 academic year, the analysis of the progress of fourth-form pupils in basic subjects has significantly increased. The quality of knowledge of pupils in the first term was $74.19 \%$, in the second term $-77.42 \%$; in mathematics in the first term -87.0 , in the second term -93.55 . There is a positive trend in the quality of students' knowledge (Table 1).

Table 1. Analysis of the progress of fourth-form pupils in basic subjects.

\begin{tabular}{|l|l|l|l|l|}
\hline \multirow{1}{*}{ Subject } & \multicolumn{2}{|c|}{$\begin{array}{c}\text { 2019-2020 academic year } \\
\text { Term 1 }\end{array}$} & \multicolumn{2}{c|}{$\begin{array}{c}\text { 2019-2020 academic year } \\
\text { Term 2 }\end{array}$} \\
\cline { 2 - 5 } & Progress & Quality & Progress & Quality \\
\hline Russian & 100 & 74.19 & 100 & 77.42 \\
\hline Mathematics & 100 & 87.10 & 100 & 93.55 \\
\hline
\end{tabular}

The analysis of the reading skills test showed that in the first term of the 2019-2020 academic year, $61 \%$ of students read above the norm, less than $26 \%$, and the results of the second quarter showed that $65 \%$ of students read above the norm, $13 \%$ - below the norm. The indicators increased by $4 \%$ and $13 \%$, respectively (Table 2 ).

Table 2. Analysis of the test of students' reading skills.

\begin{tabular}{|l|c|c|}
\hline Indicators & $\begin{array}{l}\mathbf{2 0 1 9 - 2 0 2 0} \text { academic year } \\
\text { Term 1 }\end{array}$ & $\begin{array}{l}\mathbf{2 0 1 9 - 2 0 2 0} \text { academic year } \\
\text { Term 2 }\end{array}$ \\
\hline Above normal & $61 \%$ & $65 \%$ \\
\hline Below normal & $26 \%$ & $13 \%$ \\
\hline
\end{tabular}

The learning results increase the quality of the formation of correct, conscious, expressive reading, which helps to assimilate educational information completely, does not cause difficulties in independent work with the text and problems with the full perception of the content of reading.

Like any online resource, the platform also has its advantages and disadvantages. The main advantage is interesting interactive tasks. A teacher can see the progress of each of his students, just as a parent can see the progress of each child. The portal provides an opportunity for children with special educational needs.

Our experience with the platform allows us to identify the following perspectives:

- the development of reading technology;

- to develop speech skills (monologue, dialogue); 
- to eliminate psychological barriers and fears (to speak, to read, to be afraid to make mistakes, to ask the teacher a question);

- to provide students with an individual approach;

- preparation for advanced research in computer science;

- saving teacher's time for checking and the ability to correct errors almost instantly;

- there is no "mountain" of notebooks, sheets, etc. for checking;

- effective allocation of teaching time in the classroom.

Digital technologies enrich learning in a variety of ways and provide opportunities that were previously unavailable to everyone, opening up access to a wealth of information and resources.

The studies have shown that the problem of the formation of digital literacy among students is quite acute. At this stage the school Computer Science curriculum lacks material assigned to develop students' digital abilities. The content of the existing school curriculum needs to be adjusted. The modern development of the research topic does not reflect all the aspects of the development of digital literacy. In order to ensure the integrity of the educational process and the succession formed in informatics research at different stages of school education, it is necessary to create electronic educational resources on distance learning platforms in order to develop students' digital literacy in the process of organizing independent work deliberately.

The main disadvantage of digital platforms is the payment for work on the portal. In this regard, not all students of the 4th form have the opportunity to work in the MEE. In general, it can be concluded that digital technology does help children to learn subjects more easily, reduce boredom at school and increase their motivation to learn.

Students are also starting to use gadgets for educational purposes. Teaching influence has become less authoritarian and more democratic. The use of digital technologies allows you to realize the creative freedom of the participants of the educational process.

In accordance with federal education standards, it can be concluded that it is necessary to use modern learning technologies of this type of activity in the educational process, as well as to update timely the primary communication in accordance with the dynamics of the development of the educational system.

Speaking about the use of modern educational technologies, it is necessary to pay attention to the possible forms of introducing ICT into the educational process of schools:

- distance learning;

- online training;

- educational platform;

- interactive simulators, tests, polls, etc.

Distance learning implies more independent access to education along a predetermined personal route. Online learning is carried out by teachers who create information and educational space. This form differs from the traditional form by the presence of virtual environment. Educational platforms have become widespread due to the variety of tools necessary for the productive activities of schoolchildren.

An educational platform is an Internet resource that must contain, under certain conditions, a library of educational materials provided to users.

The goal of these platforms is to provide qualitive education through digital technologies.

These platforms are relevant for children of primary school age, since use of visual methods of high-quality allow students to facilitate the process of memorizing information.

\section{Conclusions}

The analysis performed allows us to draw the following main conclusions: 
1. Russian schools, teachers and children have access to a wide and varied range of teaching materials (texts, illustrations, videos, etc.) for most of the subjects of the school curriculum. Although the subject matter of educational and technical materials lags behind the world level, in general it offers the coverage of almost all topics and the level of development of many disciplines. Most of the training materials are provided free of charge.

2. The body of this illustrative text material lacks a good navigation system, as well as a convenient tool for including it in the educational process. The task of its development is urgent.

3. Schools practically do not have a modern learning management system that could bring their educational process online. Many solutions available on the market can be upgraded to the desired functionality. This task is also relevant.

4. Providing interactive educational resources is not enough to disseminate distance learning in an active way. The existing problem is usually a test with a selected answer or a problem with one answer. As a rule, they do not use modern technical solutions. This defect does not allow teachers to realize the function of independent leadership. Moreover, most of these resources are paid. Most teachers have no experience of using them in the educational process.

5. The education system has access to many common tools for working with documents, for communication, organizing group work and feedback. But this access is rarely used. At the same time schools evidently lack comprehensive solutions, and these funds will be combined with the general system of organizing the educational process. Without this, the introduction of a distance learning format can lead to misunderstandings and confusion.

6. There is no distance learning methodology. There is practically no theoretical and practical development of the use of digital materials for a specific age (primary, secondary and high school).

7. Without a universal solution the school switched to a distance learning format completely. The urgency of this situation requires the creation of a small network of pilot schools, where the integration of various resources is tested and methods of their use are developed.

8. The main obstacle to implementation is analyzed, as well as future tools and resources - regulatory restrictions on the use of external educational services, networks and sanitary standards. It is clear that in the transition from schools to distance learning formats, it is necessary to minimize these obstacles.

9. The most important obstacle is, of course, the resource barrier. Almost all modern interactive services are developed and implemented by commercial companies. They cannot continue to support these services for free for a long time. Besides, they need funds to develop a product. That is why it is now most reasonable to allocate additional funds to schools.

The educational platform is a good source of information for teachers whose task is to select and introduce materials into the educational process. It is necessary to use these means to diversify the educational process, develop the interests of students, increase motivation for learning, etc. The active use of educational platforms and network resources will create a virtual educational environment for educational institutions of all types.

\section{References}

1. A.M. Aleksankov, The Fourth Industrial Revolution and Modernization of Education, International Experience, Strategic Priorities, 1, 53-69 (2017) 
2. D.N. Storozhilova, Actual Problems of Teaching Social Studies in the Context of the Transition to the Federal State Educational Standard, Scientific-Methodical Electronic Journal "Concept", 13, 3491-3495 (2017)

3. A.M. Aleksankov, The Fourth Industrial Revolution and Modernization of Education, International Experience, Strategic Priorities, 1, 53-69 (2017)

4. N.Yu. Ignatova, Digital Aborigines: A Side View, Open and Distance Education, 1(65), 58-65 (2017)

5. I.M. Agibova, Conditions and Factors for Organizing Effective Independent Work of Students Using Information and Communication Technologies, Bulletin of the Pomor University. Series: Humanities and Social Sciences, 5, 128-134 (2018)

6. A.A. Andreev, The role and Problems of a teacher in the e-Learning Environment, Higher education in Russia, 8-9, 41-44 (2018)

7. S.D. Karakozov, A.Yu. Uvarov, Conditions for Successful Informatization of the Educational Process, Informatics and Education, 4(273), 3-10 (2016)

8. A.B. Galanov, Methods of Telecommunication Educational Activity at School, 128 (2016)

9. D.A. Levy, The Internet-Mobilized Political Activity and the Phenomenon of Digital Diplomacy, Azimuth of Scientific Research: Economics and Management, 4(13), 96-99 (2017)

10. T.V. Skryl, A.S. Paramonov, Digital Transformation of the Healthcare Sector: Russian and Foreign Specifics, Karelian Scientific Journal, 3(20), 137-140 (2017)

11. E.V. Tailakova, M.G. Petukhova, S.B. Nosova, Formation of Motivation for Studying Mathematics of Junior Schoolchildren through the Individual Educational Platform "Uchi.ru”, Young Scientist, 52, 221-224 (2017)

12. N.I. Khosroeva, Human Capital as a Factor in the Formation of the Knowledge Economy, Azimuth of Scientific Research: Economics and Management, 4(21), 255258 (2017)

13. A.N. Chesnokov, M.M. Yakupova, S.V. Epifanov, Computer Modeling and Internet Technologies in the General Educational Process, Azimuth of Scientific Research: Pedagogy and Psychology, 4(9), 133-137 (2018)

14. L.V. Shmelkova, Human Resources for the Digital Economy: a Look into Future, Additional Professional Education in the Country and the World, 30, 1-4 (2016)

15. E-soft development / website of the company for the development of distance learning courses, Access mode: http://www.weblearn.ru/ozentre\#

16. Going the Distance: Online Education in the United States, Electronic resource, Access mode: http: //olms.cte.jhu.edu/olms2 / data / ck / sites / 336 /files/goingthedistance.pdf 